\title{
El spot de bien público: aproximación teórica y conceptual
}

Spot for social good: Theoretical and conceptual approach

O spot de televisão de interesse público: Abordagem teórica e conceitual

Eduardo Alejandro HERNÁNDEZ ALFONSO

Universidad Central “Marta Abreu” de Las Villas / ealejandro@uclv.cu

Luis Ernesto PAZ ENRIQUE

Universidad Central "Marta Abreu" de Las Villas

luisernestopazenrique@gmail.com

Chasqui. Revista Latinoamericana de Comunicación

N. ${ }^{\circ}$ 146, abril-julio 2021 (Sección Monográfico, pp. 183-198)

ISSN 1390-1079 / e-ISSN 1390-924X

Ecuador: CIESPAL

Recibido: 02-12-2020/Aprobado: 07-02-2021 


\title{
Resumen
}

El spot televisivo de bien público ha sido poco fundamentado desde la literatura científica publicada en cuanto a su estructura y funciones. Predominan las teorizaciones en torno al spot televisivo con enfoque comercial. Se planteó como objetivo del estudio fundamentar la estructura y funciones del spot de bien público. Para la obtención de resultados se emplearon métodos en los niveles teórico y empírico, fundamentalmente el análisis documental. El spot de bien público constituye un género televisivo enfocado en la publicidad social para persuadir y sensibilizar desde un soporte axiológico. Se estableció una clasificación para el spot de bien público: 1. Spot de bien público informativo, 2 . Spot de bien público educativo, 3. Spot de bien público emotivo.

Palabras clave: spot, spot de bien público, publicidad, televisión

\begin{abstract}
The spot for social good has been little supported from the published scientific literature in terms of its structure and functions. Theorizations around television spot shows that commercial is predominat. The objective of the study was to establish the structure and functions of the spot for social good. In order to obtain results, methods were used at the theoretical and empirical levels, mainly documentary analysis. The spot for social good constitutes a television genre focused on social advertising to persuade and sensitize from an axiological support. A classification was established for the spot for social good: 1. Informative spot for social good, 2. Educational spot for social good, 3 . Emotional spot for social good.
\end{abstract}

Key words: spot, spot for social good, advertising, television

\section{Resumo}

O spot de televisão de utilidade pública tem sido mal apoiado pela literatura científica publicada em termos de sua estrutura e funções. Predominam as teorizações em torno do spot de televisão com foco comercial. O objetivo do estudo foi estabelecer a estrutura e funções do ponto de bem público. Para a obtenção dos resultados, foram utilizados métodos a nível teórico e empírico, principalmente a análise documental. $\mathrm{O}$ anúncio público constitui um gênero televisivo voltado para a publicidade social para persuadir e sensibilizar a partir de um suporte axiológico. Uma classificação foi estabelecida para o spot bom público: 1. Spot bom público informativo, 2. Spot bom público educacional, 3 . Spot bom público emocional.

Palavras-chave: spot, spot de bem público, publicidade, televisão 


\section{Introducción}

Los medios de comunicación (prensa, radio, televisión) son resultado de las necesidades humanas de registro e interpretación de la realidad. Constituyen formas institucionalizadas de trasmisión masiva de contenidos que han evolucionado junto a los adelantos tecnológicos. En la actualidad se revela el hecho que además de representar la realidad también pretenden influir en los criterios, hábitos y percepciones de las personas. Forman sistemas de significados, que proporcionan patrones de lo que es normal, donde se señalan desviaciones y se hacen comparaciones (Mc Quail, 2000).

Gutiérrez, Rodríguez y Gallego (2010) entienden que los medios de comunicación constituyen conjuntos de procesos (técnicos, profesionales, estéticos, ideológicos, económicos, políticos) entre cuyas finalidades está la generación social de significados. Se logra incidir en grandes grupos de personas, dado que los mensajes se adaptan a los intereses de los consumidores o generan nuevas necesidades de información o entretenimiento. La homogenización de la sociedad constituye una de las principales tareas de las instituciones mediáticas, de tal modo incidir unidireccionalmente atendiendo a grupos etarios, sexo, clases sociales, grado de escolaridad, delimitaciones geográficas (local-provincial-nacional), entre otros.

Las funciones de los medios de comunicación se han descrito desde diversas perspectivas, Lasswell (1948) plantea tres aspectos básicos "proporcionar informaciones, proporcionar interpretaciones que hagan significativas y coherentes las informaciones, expresar los valores culturales y simbólicos propios de la identidad y de la continuidad social" (p. 10). Este autor reconoce exclusivamente la función informativa, y señala que la decodificación constituye un proceso guiado por la institución generadora del mensaje. En tanto son obviadas las posibilidades de reinterpretación de las personas que consumen los mensajes y se reproduce un poder omnipotente en los medios de comunicación.

Se corrobora desde el autor mencionado la cualidad reproductora de los medios de comunicación respecto al sistema social que ostenta el poder. En este caso se mencionan los aspectos identitarios como recursos simbólicos para trasmitir mensajes contextualizados a las personas que consumen las comunicaciones masivas. Por lo tanto, es preciso entender cómo se incorporan esos mensajes a la vida cotidiana en condiciones específicas (Cruz, 2013).

Los medios también permiten el fortalecimiento de las normas sociales, al codificar el deber ser en elementos sensoriales (sonidos, imágenes) que se decodifican desde aspectos socialmente compartidos tales como prejuicios, valores, comportamientos, entre otros. Para Lazarsfeld y Merton (1948) la trascendencia se sustenta en el abordaje de problemas periféricos o centrales de la estructura social que son identificados por la opinión pública ${ }^{1}$ o sugeridos

1 Interpretación construida a partir de acontecimientos de la vida social e influenciada por la hegemonía política. Constituye el punto de contacto entre la sociedad civil y la sociedad política, se encuentra mediada 
por los propios medios de comunicación. Aunque en esta visión aparecen atisbos de una función educativa, se orienta fundamentalmente a la preservación del orden institucional en la sociedad.

Thompson (2008) refiere que la producción institucionalizada de mensajes en los medios de comunicación suscita procesos de acumulación deinformación/ comunicación. Por tanto, se entiende que la perspectiva funcionalista de los medios de comunicación se mantiene hasta la actualidad, custodiada por las instituciones que generan las comunicaciones masivas y otras que comparten el compromiso ideológico de mantener el status quo. La preocupación fundamental continúa radicando en las apropiaciones que las personas realizan del consumo mediático y de los $u_{\mathrm{sos}^{2}}$ o de las motivaciones que impulsan estas actitudes (Wright, 1974).

Las televisiones en cualquier contexto de acción son generadoras y transmisoras de comportamientos y opiniones. Para Lull (1982) este medio interviene en actividades tales como la integración social ${ }^{3}$ y la pertenencia o exclusión a un grupo, en el aprendizaje social o en la demostración de competencia y dominio personal. En el caso de la integración comunicacional como subcategoría de la integración social, facilita la sensibilización de la población sobre determinadas temáticas y valores.

En correspondencia ejerce una función educativa, dado que la información audiovisual ${ }^{4}$ producida posibilita la adquisición de conocimientos (de tipo científico o socialmente aceptado). Los autores De Garcillán y Martínez (2014) establecen que las funciones son dinámicas en tanto se informa educando o viceversa mediante "la creación/reproducción de preferencias, de valores, de hábitos culturales, de mitos y anti-mitos, de costumbres” (p. 85). Coincidentemente los mensajes se jerarquizan acorde a la tipología de programa que se produce o de la televisora que los origina.

Sobre la base de los aspectos descritos anteriormente se considera que la televisión constituye un agente de socialización. ${ }^{5}$ Leoz $(2015, \mathrm{p} 132)$ argumenta que "ofrece modelos de conducta y juicios sobre acontecimientos, además de reforzar normas sociales y ser capaces de conformar un clima de opinión”. En la televisión se trasmiten comunicaciones visuales que condicionan formas de pensar, y aunque comparte autoridad con otros agentes de socialización

por el consenso y la fuerza (Gramsci, 1984).

2 Son evidencias observables del control que tienen las audiencias sobre el contenido y los instrumentos receptivos de la comunicación masiva (Lull, 2017).

3 Landecker (1951) distingue cuatro tipos de integración social: funcional (el papel en la vida económica y material de la sociedad), cultural (ser parte de en un grupo social que comparte normas, símbolos, sentido de vida), normativa (sanciones e incentivos que hacen eficaces las normas culturales) y comunicacional (intercambio de significados entre las personas que comparten una integración cultural).

4 Es aquella que les llega a los receptores por medio de sonidos e imágenes, lo que exige una codificación adecuada a los signos que utilizan y un canal capaz de usarlos (Sanabria, 1994).

5 La socialización ocurre de una manera más difusa, concierne al conjunto de una colectividad y afecta a una masa. 
(familia, escuela) presenta una mayor influencia dado su asincronía con la vida cotidiana.

Por su naturaleza estandarizada, la televisión se ajusta a géneros que intentan satisfacer necesidades previamente identificadas (informativas, de entretenimiento). Por otra parte, se estimula la orientación, movilización, adoctrinamiento y profundización ideológica en los consumidores (Muñoz, 2015). La evolución de la televisión ha diferenciado dos campos de acción, en lo que Merton (1965) denomina influyentes locales e influyentes cosmopolitas (a los efectos de la presente investigación se asume "nacional"). El primero se preocupa de los problemas locales, con menor referencia al contexto nacional e internacional, mientras que el segundo homogeniza las necesidades a tal punto que consigue insertarlas como parte de intereses globalizados.

Por consiguiente, los consumidores perciben, en cualquier momento, una relación directa entrela representaciónyla realidad. Esta manera de comprender la sociedad se debe a la autoridad que ostenta sobre las informaciones que proporciona. Cerezo (1996) corrobora que "a menudo se emplean frases del tipo (lo han dicho en la televisión, lo han anunciado en televisión) como marca de credibilidad". El medio consigue producir un efecto de veracidad, en el que se logra ser más legitimador que la realidad misma.

En el logro de tal propósito se tienen en cuenta dos etapas (creativa y tecnológica). En la primera se definen diversos aspectos tales como los objetivos de los programas, los temas que se abordarán y su representación en mensajes. En la segunda se determinan soluciones visuales a partir de la tecnología óptica (cámaras de video), luces, micrófonos, y la actividad de posproducción (edición, corrección, emisión). En esta dinámica se decide la influencia comunicativa, sociológica e ideológica del medio de comunicación, porque nada de lo que se expresa está sujeto a la casualidad o espontaneidad.

En la producción televisiva se emplea el binomio información-motivación con el propósito de generar identificación de los consumidores hacia los contenidos. De ahí que se reproduzca una tendencia funcionalista estructural hacia lo que Blumer (1969) reconoce como la incidencia de la institución sobre la representación colectiva. Las personas identifican en la televisión una guía de comportamiento socialmente aceptado, porque al mismo tiempo ya ha sido convencionalmente institucionalizado. Se aplica el hecho que "cuanto más se institucionaliza el comportamiento, más previsible y, por ende, más controlado se vuelve" (Berger \& Luckmann, 2006, p. 74).

Sobre una revisión de la literatura científica publicada se evidencia la ausencia de estudios dedicados a la fundamentación del spot televisivo de bien público. No pudieron ser recuperadas investigaciones que aborden teóricamente la estructura y funciones del mismo, siendo predominantes las teorizaciones en torno al spot comercial. Entonces, se planteó como objetivo del estudio: Fundamentar y conceptualizar la estructura y funciones del spot televisivo de bien público. 


\section{Metodología}

El presente estudio es descriptivo con aporte teórico. Se enfoca en clasificar el spot de bien público para su tratamiento audiovisual e investigación social. Además, sistematiza las tipificaciones del spot de bien público incluyendo el enfoque de la publicidad comercial. La evolución histórico-lógica de la comunicación evidencia un uso indistinto de la publicidad: el enfoque social entendido desde el consumo, la representación de la sociedad desde la creación o estímulo de necesidades y la jerarquización de temas de la sociedad con especial sensibilidad para su contexto.

Con tal antecedente se precisa estudiar ontológica y epistemológicamente el objeto de la investigación (spot de bien público) y no desde un diagnóstico empírico de una muestra de audiovisuales de ese género. Para la obtención de resultados se aplican métodos en los ámbitos teórico y empírico. En el nivel teórico se emplean los métodos analítico-sintético, histórico-lógico, inductivodeductivo y sistémico-estructural.

En el nivel empírico se utiliza el análisis documental clásico mediante la consulta de fuentes y bases de datos especializadas sobre las temáticas que se abordan. La técnica empleada fue la revisión de documentos. Esta facilita la localización de referentes teóricos sobre la temática en cuestión a partir de un exhaustivo análisis documental. Se emplea la información relevante recuperada de la documentación a través de los siguientes pasos:

- Determinar los objetivos de estudio documental: dirigido a identificar las fuentes que abordan la publicidad comercial y social en los medios de comunicación, las características y funciones del spot, para la realización de valoraciones críticas.

- Establecer la muestra de los documentos que serán estudiados: se establece como muestra de documentos a analizar, aquellas fuentes cuyo contenido refleje el pensamiento clásico sobre la comunicación y sociología de la comunicación; además de otros autores en la contemporaneidad que investiguen sobre esta temática. Entre los documentos a analizar se encuentran obras impresas, publicaciones seriadas, así como diversos artículos procedentes de bases de datos como: SciELO y Scopus.

- Determinar las unidades de análisis en las que se fracciona el contenido para estudiar el documento: para la recuperación de documentación en Internet se sigue como estrategia de búsqueda la formulación de los términos o palabras clave: publicidad, publicidad social, publicidad de bien público y spot televisivo. Siempre se tuvo en cuenta que, aunque el estudio se desarrolla desde la región latinoamericana, el origen de la temática y el alcance de los resultados demandan revisión de documentos en inglés.

- Elaborar las categorías de análisis: que coinciden con los términos clave planteados en el paso anterior. Dentro de las categorías de análisis 
propuestas, se establecen subcategorías que garantizan profundizar en los aspectos teóricos que se pretenden abordar: comunicación para el desarrollo, responsabilidad social de los medios de comunicación y transformación social.

- Realizar el estudio documental registrando la información: se realizó el registro de la información siguiendo la lógica de trabajo expresada en los pasos anteriores, sin perder el análisis contextual de la temática. Se logra una integración coherente de todas las ideas para, de forma armónica, entrelazar y sistematizar todos los referentes teórico-metodológicos que han abordado las temáticas mencionadas desde la década de 1948 hasta la actualidad.

- Valoración de la información obtenida: se realizarán valoraciones a partir de los presupuestos teóricos y metodológicos precisados, realizándose inferencias y argumentaciones. Finalmente, se establecen conclusiones sobre la información relevante recuperada.

\section{La publicidad de bien público}

La televisión constituye un soporte comunicativo que marcó el desarrollo de la publicidad, en tanto permite una estimulación sensorial más completa si se compara con los medios de comunicación que le antecedieron. Degrado (2005) argumenta que "el poder sugestivo de las imágenes en movimiento unido con palabras y música en el propio hogar es considerable” (p. 3). Como consecuencia la publicidad que se produce desde este medio de comunicación incide en las interpretaciones que las personas realizan sobre productos, servicios e ideas.

Si bien es un hecho que la forma comercial ha hegemonizado la actividad publicitaria, existe una modalidad que apela al bien público o social, e intenta condicionar actitudes, comportamientos y promover valores socialmente compartidos. En ambas formas se asocian los mensajes a campañas de comunicación, donde la televisión viene a formar parte de una estrategia de medios, y no un fin en sí mismo. Por tanto, los mensajes se diseñan armónicamente a través de diversos soportes publicitarios que apoyan una temática central.

La práctica publicitaria ha evidenciado una distinción entre lo social de la publicidad (función social de la publicidad), lo social en la publicidad (publicidad con causa), la publicidad de lo social (publicidad social) (Feliu, 2004). Siendo esta última la que promueve campañas en nombre de organizaciones e instituciones sobre temas relacionados con la salud preventiva, la preservación del medio ambiente y el bienestar social.

Desde el punto de vista histórico, Nos (2007) considera que las primeras campañas de publicidad de bien público eran sencillas, directas, y muy poco elaboradas retóricas y creativamente, ya que estaban más centradas en la información sobre el problema social que preocupadas por la persuasión. 
Dicho de ese modo parece una vuelta al pasado de esta forma productiva, pero en realidad constituye un modo que se reproduce en la actualidad. Lo anterior favorece una falta de eficacia a largo plazo, es decir, los mensajes no ayudan a transformar las realidades en las que trabajan, no influyen positivamente en la superación de las principales conductas de riesgo.

Con este precedente resulta complicado proveer información sobre una cuestión de interés general y al mismo tiempo promover la opinión pública ${ }^{6}$ sobre temas que preocupan. La responsabilidad social que encara la comunicación masiva en este caso es invariable, porque sin lugar a dudas, busca fortalecer la integración social en torno a problemáticas acuciantes que necesitan de la acción colectiva.

Específicamente la publicidad televisiva de bien público se inscribe en la tendencia de la comunicación para el desarrollo, ${ }^{7}$ ya que forma parte de procesos sociales que fomentan el diálogo y la adopción de decisiones locales, nacionales y regionales. Es así que numerosas iniciativas e instituciones (Unesco, ${ }^{8} \mathrm{PNUD},{ }^{9} \mathrm{FAO},{ }^{10}$ Unicef $^{11}$ ) a escala internacional integran esta forma de comunicación de masas en sus estrategias, y que afirman que el desarrollo es un proceso comunicativo (Cosude, 2016). Por lo que el trabajo de sensibilización y de persuasión hacia las personas se lleva a cabo mediante los instrumentos de la comunicación.

Bajo este principio se afirma que la publicidad televisiva de bien público tiene que fomentar el diálogo entre las personas, en un entorno social definido, ya que es el único modo de conocer las inquietudes/necesidades y estimular la participación. En esta lógica productiva se logra despertar más interés y reflejar mejor el sentir local. Cosude (2016) corrobora que se debe partir inicialmente de las preguntas ¿Qué queremos lograr? ¿Qué cambios queremos inducir?, para posteriormente jerarquizar acciones (persuadir, concientizar, motivar, movilizar, educar, recrear, empoderar, reconocer, debatir, cambiar, difundir, incidir) en torno a una problemática particular.

Por otra parte, el consumidor que se identifica vivencialmente con el mensaje, en el largo plazo puede reproducirlo en su práctica cotidiana. Por su naturaleza, esta tipología publicitaria no solo representa la realidad, sino que favorece la transmisión de alternativas y de posibles soluciones. Schmitt (2019) menciona que desencadenar reacciones como percibir, sentir, pensar, actuar y relacionarse, favorece la autoevaluación de los comportamientos.

6 Cuestiones de interés general o común, al bien común, y más concretamente a asuntos relacionados con la administración o al Estado (Price, 1994).

7 Es una disciplina de la comunicación social que facilita el nexo entre la comunicación y la gestión de proyectos.

8 Organización de las Naciones Unidas para la Educación, la Ciencia y la Cultura.

9 Programa de las Naciones Unidas para el Desarrollo.

10 Organización de las Naciones Unidas de la Alimentación y la Agricultura.

11 Fondo de las Naciones Unidas para la Infancia. 
Como bien se ha mencionado, la frustración del objetivo de una campaña publicitaria de bien público no se constata inmediatamente. Los lapsos de respuesta prolongados se relacionan con las interpretaciones individuales de la realidad sobre las que actúa la publicidad social. Álvarez (2003) enfatiza que se trata de "un proceso más largo y profundo para modificar las creencias, las ideologías y cambiar las actitudes" (p. 129). Aunque las líneas de mensaje que se generan asociadas a la temática central, con el tiempo de exposición, pueden superar el objetivo inicial y constatarse cambios anticipadamente en las personas.

Esta manera de comprender el fenómeno publicitario apunta que para introducir modificaciones resulta desventajoso ir contra las preferencias sociales, por muy negativas que estas sean para la sociedad, porque generan rechazo. Si bien hay determinadas emergencias, la sensibilidad social de los consumidores constituye una prioridad para cualquier objetivo de campaña. Ello significa asumir niveles para producir los mensajes: lo informativo (las personas necesitan conocer el tema que se aborda), lo valorativo (qué se suscita en las personas al consumir los mensajes) y la predisposición hacia la acción (cómo se va a actuar en consecuencia a lo representado).

\section{El spot de bien público}

El spot de bien público constituye una síntesis del modo productivo publicitario mencionado. Su forma básica se define como un programa con tiempo de duración menor de 120 segundos que se emite en los intermedios de los programas, "aunque los formatos más comunes son de 15, 30, 45 y 60 segundos" (Andronowicz, 2015, p. 5). En Cuba, la duración habitual de un spot televisivo es 20 segundos, aunque se usan de diez segundos para ofrecer mayor número de mensajes en un mismo tiempo. Los autores Vallejo (2017), Baraybar, Baños, Barquero, Goya y De la Morena (2017), y González, Vásquez y Farrán (2019) coinciden que el aspecto emocional que impacta esta tipología de publicidad incide en las interacciones sociales, la atención, percepción y por tanto los hábitos de consumo y comportamiento.

Se caracteriza además por desarrollar una sola idea, capitalizar los recursos visuales, no solo decir sino mostrar, contar la historia con metáforas visuales (Peña, 2010). De ahí que su orientación se base en persuadir y sensibilizar desde un soporte axiológico (valores fundamentales que forman la estructura de la sociedad). El spot televisivo tiene una exposición, un desarrollo y un desenlace o moraleja que concluye el mensaje propuesto.

La tradición de publicidad comercial que caracterizó al spot televisivo (desde 1948) también ha condicionado la producción posterior. Lo que no ha significado necesariamente una evolución favorable, dado que existen tendencias de publicidad engañosa que no representan una reivindicación para los consumidores. Los autores Capodiferro (2017) y López de Lerma 
(2018) abordan que en ocasiones se transgrede el entorno comunicativo de las audiencias y sus libertades.

Aunque el spot de bien público persigue incidir de igual modo en el deseo/ atención de los consumidores, se distingue por el espectro temático que aborda. En ese orden puede emplearse una figuración de la realidad, pero siempre orientado hacia una imagen deseable, que sea llamativa e impulse hacia un estado de mejoría en la sociedad. La especialización que demanda tal actividad, permite eliminar la reproducción de estereotipos, entendidos como patrones que, desde la televisión, simplifican temáticas sociales multidimensionales sin interpretaciones transdisciplinares. A la situación descrita se contrapone que el género televisivo no forma parte de la publicidad comercial, publicidad institucional o publicidad política, privilegiadas en la asignación de presupuesto, investigaciones y dotación de capacidades y agencias creativas (Baladrón, Manchado, \& Correyero, 2019).

El spot de bien público, a su vez, se encuentra con la dificultad de pasar desapercibido durante su exhibición (programación de cambio). Los autores Hernández, Paz, Jara y Caballero (2019), y Rodríguez, Rodríguez y Espinosa (2019) abordan indistintamente que la jerarquización de los mensajes publicitarios recae en decisiones de las televisoras y sus intereses, por tanto, el tiempo asignado tiene igual dependencia de este criterio. La situación anterior determina para este género televisivo la optimización de la síntesis visual y el apego a recursos de tipo emocional que dinamicen la atención. Es decir, una correspondencia entre lo que se observa y lo que se siente (Arnheim, 2006), definitivamente es un medio para lograr objetivos no solo perceptivos sino persuasivos.

El género televisivo en cuestión es útil proporcionando información que posibilite la toma de decisiones. Mediante del esquema aristotélico de narración introducción/desarrollo/desenlace) o de disímiles formas creativas, se presentan problemáticas y soluciones en el mismo proceso de representación/ interpretación/decodificación. Sin embargo, los mensajes contenidos en los spots no son infalibles, Martín-Barbero (1991) asegura que hay una gran distancia entre la intención del emisor y la lectura del receptor.

En este orden se afirma que la producción de un spot aislado, sin responder a ninguna campaña de comunicación de bien público, no alcanza resultados a largo plazo. Al hecho de producir empíricamente el género se le asocian también incorrectas segmentaciones etarias para los grupos en que se pretende incidir o una saturación de información sobre determinada temática. Un inadecuado diagnóstico de necesidades y planificación de la producción, limita la atención selectiva de los consumidores, según Díaz-Guzmán (2009) "los spots deben ser comprendidos al mismo tiempo que se ven" (p. 124).

El poder enfático del spot refuerza la tematización. Se transforman "un cierto número de acontecimientos y hechos distintos, en un único ámbito de importancia" (Wolf, 1987, p. 99). La función de este procedimiento radica en la 
selección de los temas para depositar la atención de las audiencias y lograr su movilización. En esta lógica pueden coexistir como acontecimientos relevantes solo los contenidos de interés para las televisoras.

Ramonet (2006) afirma que "los spots venden sueños, seducen con una promesa de satisfacción" (p. 18). El enfoque comercial privilegia la manipulación para situar como objetos del consumo a las audiencias. Mientras que el bien público adopta la persuasión como estrategia para favorecer el cambio de comportamientos perjudiciales en el orden individual o colectivo. Independientemente del poder seductor atribuido a los spots, es la enfatización un elemento esencial para cumplir el objetivo de los contenidos.

A partir de un análisis documental realizado en la literatura científica publicada en torno a la categoría spot de bien público se identificó la ausencia de clasificaciones que especifiquen su alcance y rasgos distintivos. En el tratamiento del género se constata una homogenización de los recursos expresivos para reflejar la vida cotidiana. El hecho de intentar imponer fórmulas productivas para representar problemáticas diversas, obstruye la reflexión individual y colectiva.

A propósito, únicamente se identifican aportes para la comprensión de la categoría spot de bien público fundamentalmente desde estudios de casos, en los que se asume como espacio comunicativo (Peña, Escalona, \& Reyes, 2012), información relevante y novedosa (Pons, 2013), fuente de información (Hernández, Paz, \& Martínez, 2019), medio para la diferenciación (Peña, 2010), mecanismo retórico (Benet \& Nos, 2003), comparación o alegorías (Tuominen \& Kotilainen, 2012). Pero es en la publicidad comercial donde se identifican clasificaciones para el spot que constituyen antecedentes para una posterior especificación en la categoría bien público.

Díaz-Guzmán (2009) propone cuatro tipos de spots fundamentales, según el modo en que introducen los mensajes: los informativos, los testimonialesvivenciales, los lúdicos y los de performance.

- Informativos: Se realizan en la fase inicial de la promoción del producto (comercial o social), deja por sentado las ideas de algo que va a suceder, generalmente se emplean en la primera fase de las campañas publicitarias.

- Testimonial-vivencial: Cuentan una historia, escenifican una situación que conduce a destacar el producto. El esencialmente vivencial es aquel que se basa en la experiencia real de una persona acerca de un hecho.

- Lúdicos: Se crean con el propósito de lograr el recuerdo, juegan con el espectador, este en ocasiones no entiende bien de que se está hablando.

- Performance: Son muy utilizados en las campañas publicitarias actuales, al principio el espectador no entiende nada, pero al final saben lo que es, se dan ideas para que el receptor entienda lo que mejor le sea del producto. 
Por otra parte, González-Castro (1997) amplia la clasificación con cinco tipos de spot según el efecto que provoca en los consumidores: fijación, asociación, identificación, dependencia y reiteración.

- Fijación: Estos buscan que la idea se sedimente en la mente del sujeto, suelen ser simples en sus propuestas, con explicaciones breves, para que algunas pocas cosas, pero bien precisas, se queden bien sujetas en la mente.

- Asociación: Pretenden un carácter transitivo de significados, al enjuiciar a partir de la lógica siguiente, por ejemplo, si un hotel es para gente de clase y usted es una gente de clase, este es el hotel que usted necesita.

- Identificación: Son para que el sujeto aprenda a distinguir el mensaje entre cientos de ellos, a identificar el producto fácilmente, sin importar demasiado si sabe sus características o cualidades que lo hacen mejor o peor.

- Dependencia: Llevan al destinatario a creer que sin el producto ya no puede ser feliz o le falta algo esencial en la vida; la ausencia del producto tiene la significación de una carencia psicológica prioritaria, que lo llevará al estrés o la depresión, como sucede con la dependencia alcohólica o las drogas.

- Reiteración: Aportan nuevas cualidades a un producto ya aceptado por el público, ya admitido en el mercado.

En el caso del spot de bien público se toma en cuenta los rasgos distintivos del género en la publicidad comercial, pero se reconoce que la diversidad de temáticas de índole social, necesita mayor flexibilidad en la concepción de estos audiovisuales. Por ello se proponen las siguientes clasificaciones:

- Spot de bien público informativo: Se representan las causas de una problemática social y sus consecuencias en el orden individual y colectivo. Para lograr tal propósito se muestran cifras alarmantes y argumentos de especialistas sobre el beneficio de cambiar estilos de vida y comportamientos perjudiciales. Esta tipología es empleada para introducir determinada temática y ampliar sistemáticamente el conocimiento sobre la misma. Se pretende representar la realidad tal y cómo se desarrollan los acontecimientos. Se apela a la cognición del consumidor, pero el exceso de información contenida en las voces, imágenes y los textos escritos atenta contra la memoria episódica.

- Spot de bien público educativo: Persiguen enseñar sobre una temática o problemática social. Se explica mediante los contenidos con el fin de lograr la mayor reflexión posible en los consumidores. Establece nexos entre diferentes contextos donde se reproducen problemáticas similares. El tratamiento de la temática abordada se desarrolla a partir de 
la contraposición de información. Se le asocian formas de presentación tales como: antes-después, correcto-erróneo, aquí-allá. El hecho de marcar diferencias sobre contextos donde se desarrollan buenas y malas prácticas, constituye un estímulo para grupos sociales que se aluden ante tales desafíos. En este spot se muestra la posibilidad de generar aprendizajes ${ }^{12}$.

- Spot de bien público emotivo: Busca generar sensaciones exacerbadas ante una problemática social en particular. Facilita conectar el problema con emociones (repulsión, aceptación, desconcierto, inquietud). Se emplea recursos hiperbólicos que no son fácilmente descubiertos por los consumidores para alterar su representación de la realidad y compulsar a la acción. Privilegia la función persuadir sobre la de enseñar, por lo que privilegia un enfoque menos reflexivo. Busca lograr cambios coyunturales ante situaciones concretas.

\section{Conclusiones}

La televisión como cualquier medio de comunicación, es resultado de la sociedad que lo gesta. Por ese motivo, su uso intensivo para generar ingresos económicos no constituye per se una barrera hacia transformaciones enfocadas al bien común o público. En tanto la génesis de la dificultad radica en quien ostenta la titularidad del medio, dado que impone sus intereses y estimula o desconoce causas sociales. Necesariamente tampoco instituye una limitación el hecho de combinar la publicidad comercial y la social, en tanto esta última logre capitalizar los intereses, necesidades y problemáticas de los consumidores.

La publicidad social constituye una forma de producción institucionalizada de símbolos que repercute en la integración, la pertenencia y el aprendizaje social. Este medio de comunicación interviene en la generación de significados e incide de forma masiva en la transformación de la sociedad. Aspecto que refuerza la necesidad de representar desde las televisoras las problemáticas de los territorios, sus tradiciones, el acontecer cotidiano, que compulse a los habitantes a priorizar una propuesta cercana a sus intereses. De ese modo, favorecer el diálogo entre productores-consumidores y por ende la representación de las necesidades de la opinión pública.

El spot de bien público constituye un género televisivo enfocado en la publicidad social. Se produce como parte de una campaña de comunicación que pretende transformar actitudes y percepciones que pueden perjudicar la sociedad. Sobre la base del esquema aristotélico de narración (introducción/ desarrollo/desenlace) o de disímiles formas creativas, se presentan problemáticas y soluciones en el mismo proceso de representación/

12 Basado en la recepción se refiere a la situación donde lo que se debe aprender es presentado en lugar de ser descubierto. Solo se le exige que comprenda el material de una manera significativa, que lo interiorice y lo haga disponible para un uso futuro (Ausubel, 2002). 
interpretación/decodificación. Su orientación se basa en persuadir y sensibilizar desde un soporte axiológico (valores fundamentales que forman la estructura de la sociedad).

Se estableció una clasificación para el spot publicitario de bien público. Las tipologías del mismo son: 1. Spot de bien público informativo, 2. Spot de bien público educativo, 3. Spot de bien público emotivo. Para realizar el género televisivo se debe contextualizar a la realidad que lo demanda. Asimismo, se manifiesta una relación holística entre las tipologías, dado que una misma problemática puede suscitar el empleo sistemático y organizado de todas, entendiendo que para lograr determinada transformación social se debe transitar por las actividades: ampliar sistemáticamente el conocimiento, lograr la mayor reflexión y compulsar a la acción.

\section{Referencias bibliográficas}

Álvarez, A. (2003). Publicidad social: enfoques y métodos de análisis. En V. Benet, \& E. Nos (Eds.), La publicidad en el tercer sector: tendencias y perspectivas de la comunicación solidaria. Barcelona: Icaria.

Andronowicz, N. (2015). El spot publicitario de cinco segundos. Publicidad eficaz para nuevas redes sociales y video on-demand. Palermo: Universidad de Palermo.

Arnheim, R. (2006). Arte y percepción visual. Psicología del ojo creador. Madrid: Alianza Editorial.

Ausubel, D. (2002). Adquisición y retención del conocimiento. Una perspectiva cognitiva. Barcelona: Paidós.

Baladrón, A., Manchado, B., \& Correyero, B. (2019). La investigación sobre publicidad en la universidad española. Características y temáticas de las tesis doctorales (1976-2016). Revista Latina de Comunicación Social, 74(2019), 767-785.

Baraybar, A., Baños, M., Barquero, O., Goya, R., \& Morena, A. de la (2017). Evaluación de las respuestas emocionales a la publicidad televisiva desde el Neuromarketing. Comunicar, 25(52), 19-28.

Benet, V., \& Nos, E. (2003). La publicidad en el tercer sector. Tendencias y perspectivas de la comunicación solidaria. Barcelona: Icaria.

Capodiferro, D. (2017). La insuficiencia de la regulación europea sobre los límites de la publicidad comercial. Estudios de Deusto: revista de la Universidad de Deusto, 65(1), 15-43.

Cosude. (2016). Comunicación para el desarrollo. Una guía práctica. Suiza: Agencia Suiza para el Desarrollo y la Cooperación (Cosude).

Cruz, M. (2013). Los medios masivos de comunicación y su papel en la construcción y deconstrucción de identidades: apuntes críticos para una reflexión inconclusa. Bibliotecas. Anales de investigación, 9(9), 189-199.

Degrado, D. (2005). Televisión, publicidad y comunicación. Comunicar, 25(2005), 1-7.

Díaz-Guzmán, K. (2009). Fundamentos de publicidad para comunicadores sociales. Colombia: Crucet \& Asociados.

Feliu, E. (2004). La publicidad social. Madrid: Fundación General de la Universidad Complutense de Madrid.

Garcillán, M. de, \& Martínez, G. (2014). Las funciones de los medios de comunicación en la vida de una persona mayor. Revista de Comunicación de la SEECI, 35(2014), 76-95. 
González, C., Vásquez, P., \& Farrán, E. (2019). Effective communication models in advertising campaigns. A strategic analysis in the search for effectiveness. Communication E Society, 32(4), 109-124.

González-Castro, V. (1997). Para entender la televisión. La Habana: Editorial Pablo de la Torriente Brau.

Gramsci, A. (1984). Cuadernos de la cárcel. Ciudad de México: Era.

Gutiérrez, B., Rodríguez, M. C., \& Gallego, M. C. (2010). El papel de los medios de comunicación actuales en la sociedad contemporánea española. Signo y Pensamiento, 29(2010), 268-285.

Hernández, E., Paz, L., \& Martínez, Y. (2019). Documento audiovisual. Consumo, procesamiento y análisis. Santa Clara: Feijóo.

Hernández Alfonso, E., Paz Enrique, L. E., Jara, D., \& Caballero, M.T. (2019). Indicadores para constatar las expresiones de participación en la producción televisiva. Cuadernos de Documentación Multimedia, 30(2019), 207-228.

Landecker, S. (1951). Types of integration and their measurement. American Journal of Sociology, 56(4), 332340.

Lasswell, H. (1948). The structure and function on communication in society. Nueva York: Harper.

Lazarsfeld, P., \& Merton, R. (1948). Mass Communication, Popular Taste and Organized Social Action. Nueva York: Harper.

Leoz, D. (2015). La influencia de los medios de comunicación en el proceso de socialización y la importancia de la coeducación para la igualdad. Achetetepé, 11(2015), 131-140.

Lull, J. (2017). Los usos sociales de la televisión. Recuperado de http://www.jameslull.com/ losusos.html

López de Lerma, J. (2018). La protección constitucional del consumidor frente a la publicidad engañosa. Methaodos. Revista de Ciencias Sociales, 6(1), 94-107.

Martín-Barbero, J. (1991). De los medios a las mediaciones. Barcelona: Gustavo Gilli.

Mc Quail, D. (2000). Introducción a la teoría de la comunicación de masas. Barcelona: Paidós.

Merton, R. (1965). Teoría y estructuras sociales. Ciudad de México: Fondo de Cultura Económica.

Muñoz, A. (2015). Los medios de comunicación de masas como factores de la vida política. (Tesis doctoral), Universidad Complutense de Madrid, Madrid.

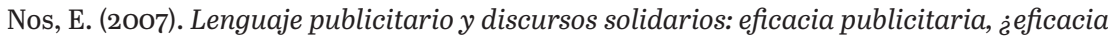
cultural? Castellón de la Plana: Universitat Jaume I.

Peña, A., Escalona, I., \& Reyes, N. (2012). Los elementos semióticos. Su relación con la comunicación para estimular la comprensión de textos desde tempranas edades. Santiago, 128(2), 321-335.

Peña, P. (2010). El spot electoral: la retórica del audiovisual. Recuperado de http://ae-ic.org/ malaga2010/upload/ok/245.pdf

Pons, G. (2013). Guía de Fondos: "Patrimonio Fotográfico Placeteño. Santa Clara: Universidad Central "Marta Abreu" de Las Villas.

Price, V. (1994). La opinión pública. Esfera pública y comunicación. Vol. 2. Barcelona: Paidós.

Ramonet, I. (2006). Propagandas silenciosas. Masas, televisión y cine. La Habana: Fondo Cultural del ALBA.

Rodríguez, G., Rodríguez, R., \& Espinosa, L. (2019). Construcción de la imagen país Cuba: Análisis de la conformación de la identidad nacional desde el spot publicitario. Cuadernos.info, 44(2019), 241-256. 
Sanabria, F. (1994). Información audiovisual. Teoría y técnica de la información radiofónica y televisiva. Barcelona: Bosch Comunicación.

Schmitt, B. (2019). Experiential marketing. Barcelona: Deusto.

Thompson, J. (2008). Ideología y cultura moderna. La Habana: Félix Varela.

Tuominen, S., \& Kotilainen, S. (2012). Pedagogía de los medios y alfabetizaciones informacionales. Moscú: Instituto para las Tecnologías de la Información en Educación.

Vallejo, G. (2017). La publicidad emocional como estrategia de mercadotecnia: oportunidad para las compañías. Quid. Investigación, Ciencia y Tecnología, 29(2017), 13-21.

Wolf, M. (1987). La investigación de la comunicación de masas. Barcelona: Paidós.

Wright, C. R. (1974). Functional Analysis and Mass Communication Revisited. New York: Katz E. 